\title{
A Review of Internet Usage among Minority-Owned Businesses in the United States
}

\author{
Millicent Lownes-Jackson and Retta Sweat Guy \\ Tennessee State University, Nashville, Tennessee, USA
}

\author{
mlownes@tnstate.edu; rguy@tnstate.edu
}

\begin{abstract}
This study conducts a review of Internet usage among minority-owned businesses in the United States. The National Directory of Minority-Owned Business Firms was used to develop a national sampling frame in which 483 businesses were selected to participate in this study. An online survey containing a mixture of Likert scale, multiple choice, and yes/no questions was deployed on September 30, 2009 thru November 25, 2009. The findings indicate that a large percentage of the minority-owned businesses are using the Internet for economic opportunities which include marketing, advertising, and selling products and services, and disseminating company information.
\end{abstract}

Keywords: Internet usage, minority-owned business, e-commerce, Web presence, website

\section{Introduction}

The Internet has changed the way in which businesses operate and communicate with its customers, suppliers and vendors. The Internet has come a long way from its origins as a mainly research-oriented system to its current configuration incorporating the World Wide Web.

The emergence and interest in the Internet has spawned an abundance of publications that include new journals, books and articles. Through the review of academic writing and the investigation efforts of a number of researchers and organizations, an in-depth literature review identifies those utilizing the Internet and reports on a range of opportunities as well as problems that are affiliated with the integration of information technology with businesses.

McBride (1997) administered a survey in the United Kingdom (UK) and discovered that many businesses found the Internet suitable for e-mailing, marketing, and selling; while, confidence in security and Internet connection was considered as barriers. More than a decade ago, businesses in the UK reported using the Internet as peripheral to their main business activities. Nevertheless, when asked why they decided to establish a Web presence on the Internet, business owners' responded with the following:

$\circ$ A presence on the Internet demonstrated the technical competence of the business

Material published as part of this publication, either on-line or in print, is copyrighted by the Informing Science Institute. Permission to make digital or paper copy of part or all of these works for personal or classroom use is granted without fee provided that the copies are not made or distributed for profit or commercial advantage AND that copies 1) bear this notice in full and 2) give the full citation on the first page. It is permissible to abstract these works so long as credit is given. To copy in all other cases or to republish or to post on a server or to redistribute to lists requires specific permission and payment of a fee. Contact 0HPublisher@InformingScience.org to request redistribution permission. and showed that it was

keeping up with the technology. (management) consultancy)

- The Internet is a marketing tool. This is particularly valuable for a small company, which is specialized and has a global market. (scientific instruments company) 
- The Internet provides ease of access to clients and partners, particularly internationally. (engineering company)

Also, their responses as to the benefits expected from being attached to the Internet included:

- International communication with customers and suppliers is facilitated. (engineering company)

- Reduced expenditure on newspaper-based advertising, particularly classified advertising. (recruitment consultants)

- A higher international profile. (botanical gardens)

- Enhanced image, looks like we're at the cutting edge of IT; good marketing exercise. (car hire company)

As more Canadians are taking to the Internet, so too are many small and medium-sized businesses. Various studies of Internet use among businesses in Canada have consistently shown continuous growth in the last few years boasting an overwhelming number of businesses online (BC Stats, 2001).

The Canadian Federation of Independent Businesses (CFIB) also reports strong growth in Internet use by small and medium-size businesses with $69 \%$ of business owners actively using the Internet (2000). The results of this study indicate that the size of a business impacts Internet use with nearly all businesses employing more than 100 workers are connected to the Internet; $80 \%$ of businesses employing 20-99 workers are connected; $71 \%$ of businesses employing 5-19 workers have Internet connection; and $60 \%$ of businesses employing less than 5 workers are connected to the Internet. Of the businesses surveyed, $34.5 \%$ of those using the Internet have a designated website and conduct transactions associated with buying and/or selling online. The other half $(34.5 \%)$ use the Internet only to browse or use e-mail.

Lowndes (2002) examined Internet usage of 698 Australian businesses. A survey administered by the Melbourne Institute of Applied Economic and Social Research reported that $482(69 \%)$ of the surveyed businesses have Internet access while only $153(22 \%)$ with access also have a web page. Of the $22 \%$, a majority of the businesses indicate that they use the Web page to:

(a) provide information about the business;

(b) advertise the business' own products; and

(c) provide an enquiry or contact facility for their customers (p. 5).

Of the 482 businesses with Internet access, 140 (29\%) reported gains in revenue from purchasing activities while only $61(13 \%)$ businesses reported gains in revenue from selling via the Internet; $44 \%$ reported using the Internet to search for the availability or cost of goods and services; more than $50 \%$ use the Internet to access government services while one-fifth use it for the electronic lodgement of taxation forms or payments. In summary, the key areas of growth in usage among Australian businesses include ordering goods and services from other organizations, receiving invoices from other businesses and utilizing banking and financial services.

Nearly a decade after the initial reports, Donner (2006) examined Internet usage of small businesses in Urban India by means of interviews and observational visits. Forty-seven small and informal businesses were selected from urban Bangalore based on criteria that included size of business and industry. Specifically, all businesses selected had less than 5 employees and were comprised of one-third manufacturing, one-third retail, and one-third service and other miscellaneous businesses.

Data collection consisted of a mix of structured, closed-ended survey questions and open-ended, semi-structured interview questions. The demographics of the respondents were young, well educated and prosperous with above average technology knowledge and skills. The results indicated 
that only $16(34 \%)$ of the respondents were classified as Internet users; hence, the more intensive users with broadband access support complex businesses. Donner (2006) provides the following examples of Internet usage for more multifaceted activities:

(a) the courier used the Internet to link up to online package tracking systems;

(b) the manufacturing of packing material used the Internet to pay bills;

(c) The perfume manufacturer used it to source raw material and contact dealers as well to pay bills;

(d) the manufacturer of foodstuffs used the Internet to research new products; and

(e) the musician used his broadband connection to record, play and share music (p. 10).

These behaviors reflect the more complex and formal communication and information needs of the businesses. However, some of the Internet users stressed more personal, less instrumental uses for the technology. For example:

(a) the operator of the day-care center talked about using her husband's broadbandenabled computer to browse the Internet and copy CDs; and

(b) the Xerox shop owner and the librarian both surveyors of information-related services, stressed that the Internet has more appeal to them for personal pursuits rather than for their businesses (p. 11).

\section{Methodology}

The United States National Directory of Minority-Owned Business Firms was used to develop a national sampling frame of minority-owned businesses. According to the Equal Employment Opportunity Commission (EEOC) guidelines, minority, also known as the protected class, is used to mean groups within the United States that differs in race from the dominant group such as those listed below.

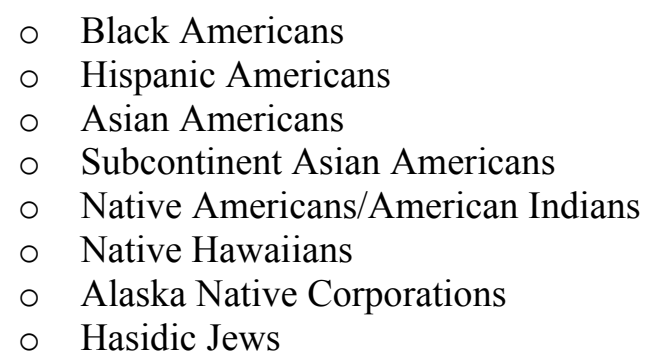

Business owners were selected for inclusion in the national directory based on the following criteria:

- Principal owner(s) or shareholders shall be members of a minority group who are American citizens or who have permanent residence in the United States.

- Collectively, principal owner(s) or shareholders shall own at least $51 \%$ of the business.

- Principal owner(s) or shareholders shall have dominant control over the business and participate in the day-to-day operations.

An online survey was created using Qualtrics software and contained a mixture of likert scale, multiple choice, and yes/no questions. Deployment of the online survey began September 30, 2009 thru November 25, 2009. Of the 483 surveys administered, 162 were returned due to closed e-mail accounts or diversion to spam (junk e-mail). The total number of minority-owned businesses that completed the survey was 83 which represent a response rate of $26 \%$. 
The following information provides an in-depth profile of those minority businesses that participated in the study. The majority of the businesses $(68 / 83 \%)$ were located in the south, $2(2 \%)$ were located in the northern part of the country, $8(10 \%)$ were located on the east coast, $1(1 \%)$ were located in the mid-west, and $3(4 \%)$ reported "other" locations. The nature of the businesses included 11 (13\%) Retail, 46 (55\%) Service, 3 (4\%) Wholesale, 3 (4\%) Manufacturing, 32 (39\%) Consulting, 7 (8\%) Construction, 11 (13\%) Educational Services, 6 (7\%) Health Care and Social Assistance, 2 (2\%) Transportation and Warehousing, 2 (2\%) Repair and Maintenance, and 8 $(10 \%)$ reported as other.

In terms of the organizational structure, $37(45 \%)$ were operating as a sole proprietorship, $5(6 \%)$ as a partnership, $37(45 \%)$ as a corporation, $2(2 \%)$ as a nonprofit, $1(1 \%)$ as a charitable organization, and $6(7 \%)$ reported other. The majority of the businesses employ less than 100 workers with 43 (52\%) employing 1-5, 7 (8\%) employing 6-10, 5 (6\%) employing 11-20, 2 (2\%) employing 21-30, 1 (1\%) employing 31-50, and 2 (2\%) employing 51-100. Lastly, more than $46(57 \%)$ of the businesses earn less than $\$ 100,000$ annually, 23 (28\%) earn annual incomes between $\$ 100,000$ and $\$ 500,000$, and $12(15 \%)$ earn annual incomes over $\$ 500,000$.

\section{Findings}

Absolute frequency statistics were used to determine how minority-owned businesses in the United States are utilizing the Internet.

To determine to what extent minority-owned businesses rely on the Internet, we posed an initial question that offered a statistical breakdown of those companies operating a dedicated website. Figure 1 shows that $66 \%$ of the respondents reported operating a dedicated website for customers, supplier, and/or investors. In contrast, only $22 \%$ do not operate a site, however, $12 \%$ are in the process of creating a website.

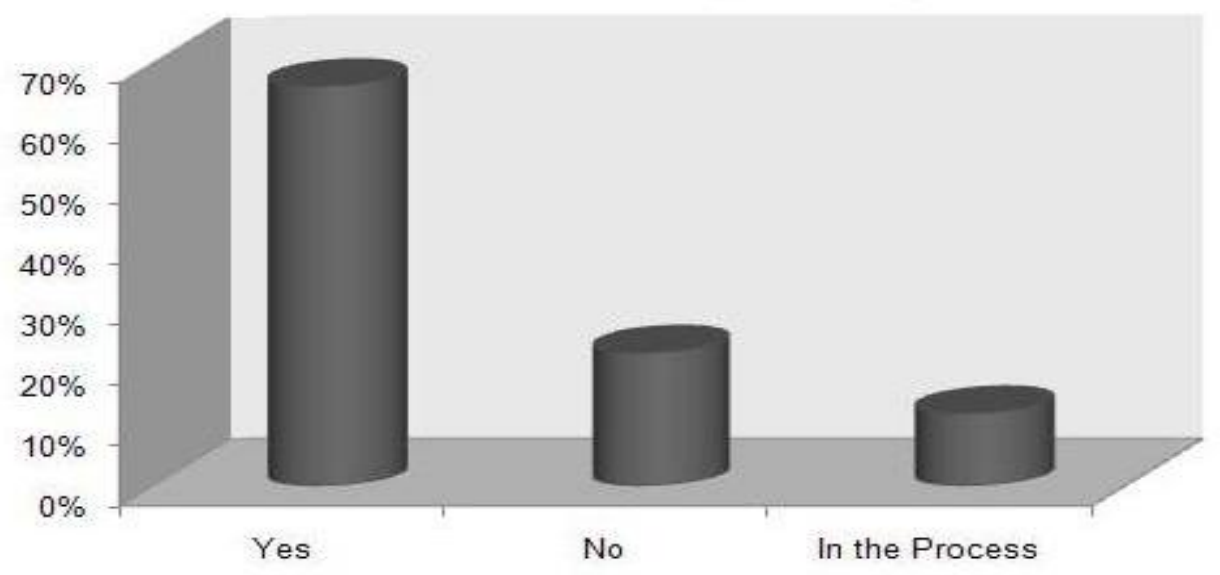

Figure 1: Does your company operate a dedicated website for customers?

To determine whether minority-owned businesses with established websites were mere extensions of a brick-and-mortar business or exclusive Internet companies, respondents were queried on the subject. When asked how they would classify the company website, the majority of the respondents classified their websites as an extension of a brick and mortar business $(60 \%)$ while only $19 \%$ were operating exclusively as an Internet-based business (see figure 2 ). Others (27\%) were classified as home-based, promotional, both brick and mortar and Internet-based. 


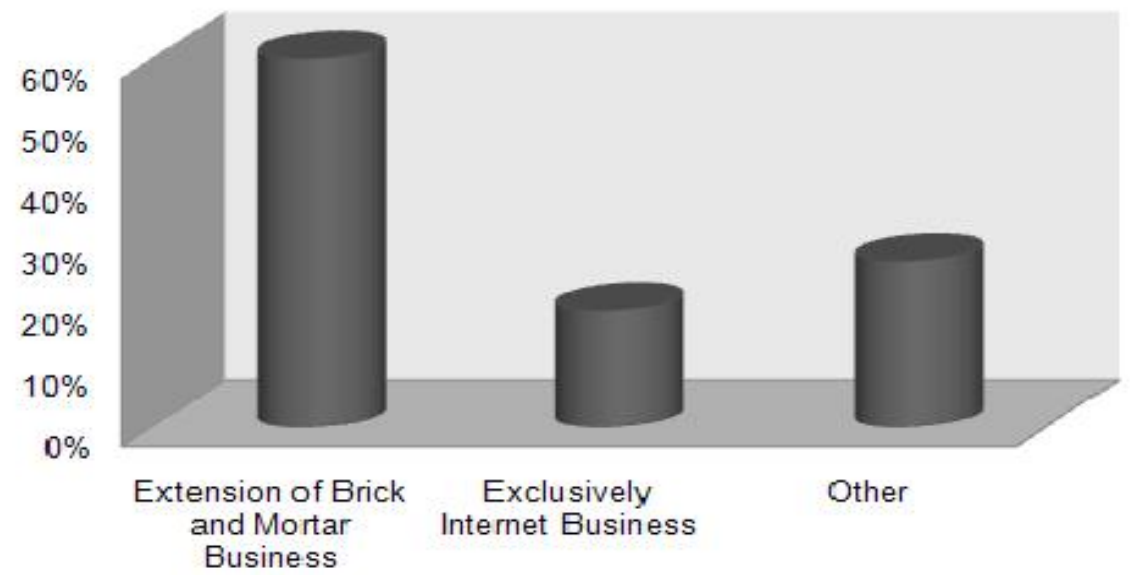

Figure 2: How would you classify your company website?

The survey revealed that minority business owners utilize the company website for a variety of purposes (see Figure 3). Over 90\% use the website for marketing and advertising purposes, 77\% use it for informational purposes, $72 \%$ use the website as a communication medium (eg. e-mail), $44 \%$ use it to obtain information from potential customers and $39 \%$ use the website to sell company products.

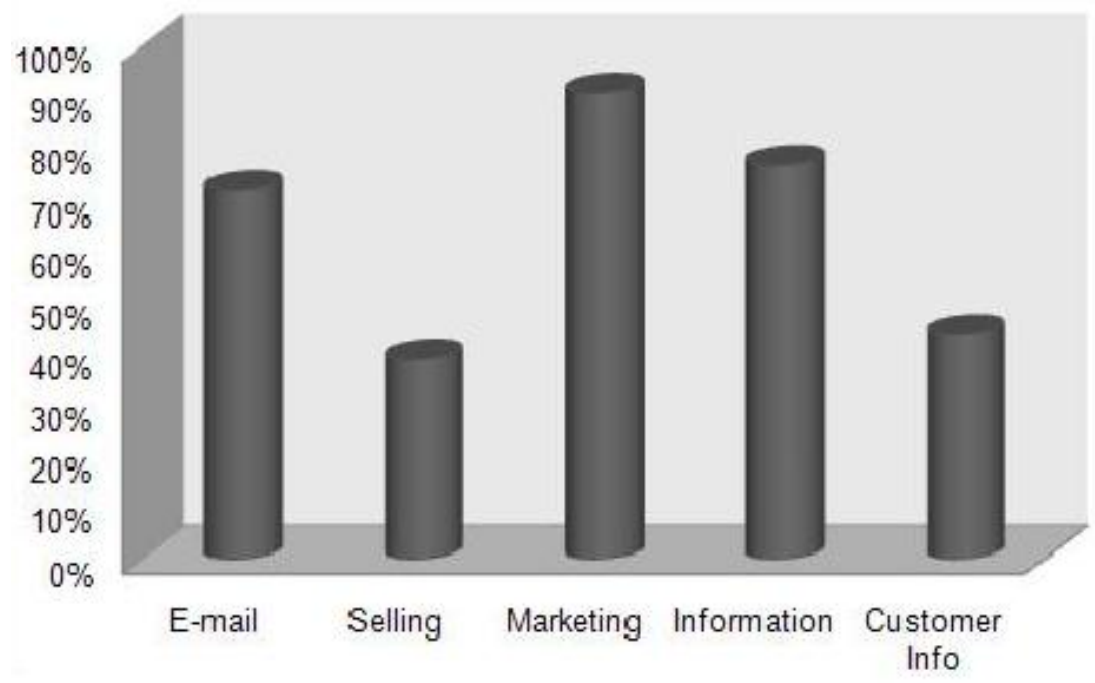

Figure 3: How is your company utilizing the website?

To uncover reasons why businesses were managed without a Web presence, respondents were asked why their company did not operate a dedicated website. The most profound reason was that the company was service oriented and not product driven (31\%), 24\% reported that the company lacked the internal expertise in Web development and management, $21 \%$ cited problems with the company infrastructure, $17 \%$ claims that their product does not lend itself to marketing and/or selling online, and 10\% stated it was too costly (see figure 4). Additionally, a small number of respondents (7\%) felt that the company size could not handle the additional workload generated from operating a website and 3\% noted that their company only sells to distributors. 


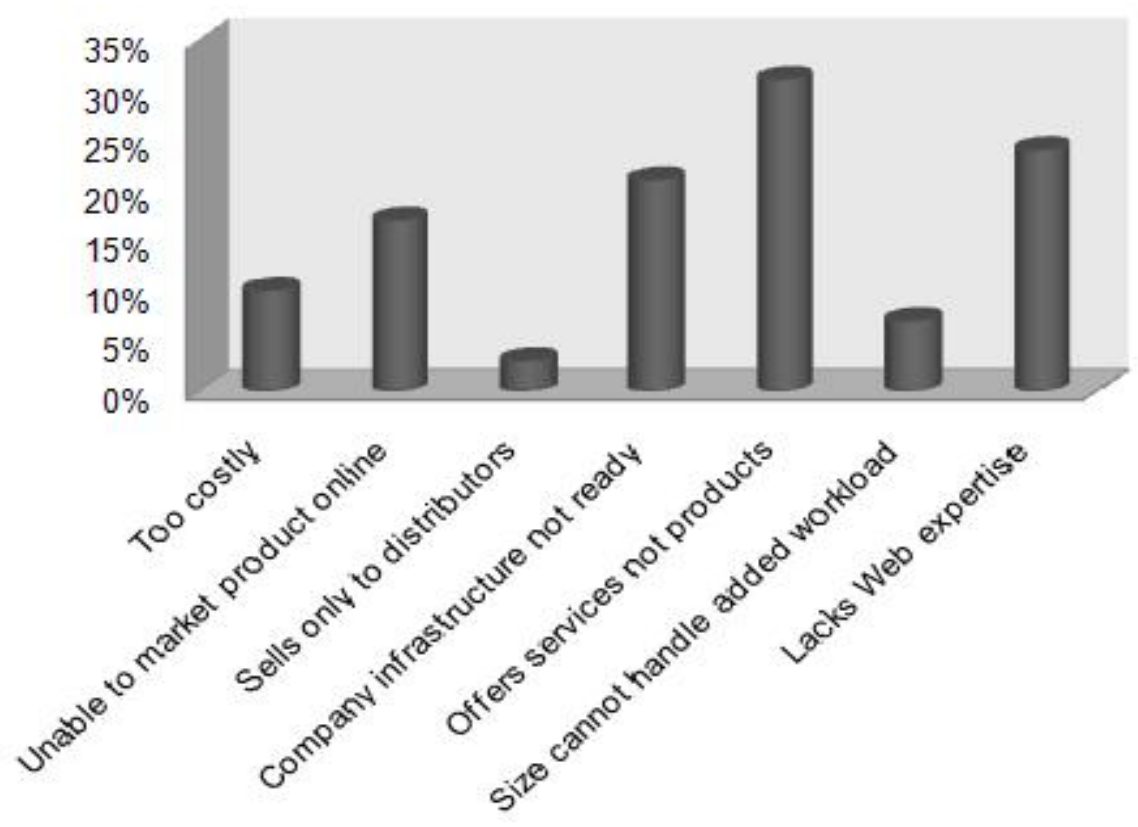

Figure 4: If your company does not operate a dedicated website, indicate reasons why?

\section{Conclusion}

The Internet is a dynamic environment, while there are many risks involved with change, there can be many benefits. Through an online survey, we have identified Internet uses reported by minority business owners.

The survey data confirms the adoption of the Internet by a majority of minority-owned businesses, which is comparable with a number of global studies whereby business owners are opting for designated company websites (British Columbia, 2001; Lowndes, 2002; McBride, 1997). Additionally, there has been much debate regarding the viability of brick-and-mortar versus exclusive Internet businesses. Despite the advantages of operating an Internet-based business, the current study suggests that minority business owners rely on a combination of on-ground and on-line convention for selling company products and services, disseminating company information and establishing new target markets.

As echoed in earlier studies (British Columbia, 2001; Donner, 2006; Lowndes, 2002; McBride, 1997), the survey revealed that minority-owned businesses use the Internet for a variety of purposes that include marketing, advertising, and selling products and services; disseminating company information; and communicating via e-mail to customer base, suppliers, and investors.

In general, minority-owned businesses are using the Internet for economic opportunities as measured by the large percentage of companies with Web presence and activities. Notwithstanding the apparent importance of the Internet for general business operations, there are still a significant number of minority-owned businesses that do not utilize the medium. Leaving aside revenue, barriers to Internet usage are quite clear. Despite the apparent potential of the Internet, there is a paucity of data that would allow a more thorough investigation of barriers to Internet usage. 


\section{References}

Bartlett, J., Kotrlik, J., \& Higgins, C. (2001). Organizational research: Determining appropriate sample size in survey research. Information Technology, Learning, and Performance Journal, 19(1), 43-50.

British Columbia Stats. (2001). Small business on-line: Internet use among SMEs. Small Business Quarterly, pp. 1-5.

CFIB. (2000). E-business update: Internet usage among small and medium-sized firms-CFIB Mid-Year Survey Results.

Donner, J. (2006). Internet use (and non-use) among urban microenterprises in the developing world: An update from India. Paper prepared for AOIR 7.0, Brisbane, Australia.

EEOC. (2007). Equal employment opportunity terminology. The U.S. National Archives and Records Administration: General Information leaflet, Number 1. Retrieved from http://www.archives.gov

Janis, F. (2000). Technology transfer e-commerce. Innovation: Management, Policy \& Practice, 3(3), 3037.

Johnson, T. (2008). National directory of minority-owned business firms. Bethesda, MD: Business Research Services, Inc.

Loundes, J. (2002). Business use of the internet in Australia. Melbourne Institute Working Paper No. 20/02; Melbourne Institute of Applied Economic and Social research: Victoria, Australia.

McBride, N. (1997). Business use of the internet: Strategic decision or another bandwagon? European Management Journal, 15(1), 58-67.

\section{Biographies}

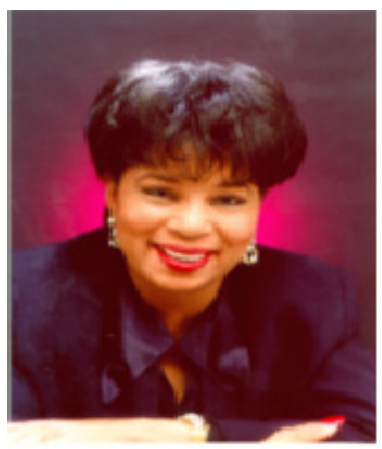

Dr. Millicent Gray Lownes-Jackson is the Associate Dean of the College of Business at Tennessee State University. She is a small business specialist, author of 15 books, an entrepreneur, newspaper columnist, researcher, certified small business coach, and a tenured Professor of Management. Dr. Lownes-Jackson's educational background includes a Bachelor of Business Administration Degree from Fisk University. She also has a Master of Business Administration Degree and a Doctor of Philosophy Degree, both of which were conferred by Vanderbilt University. Dr. Lownes-Jackson has many research articles, publications and talk show appearances to her credit. She has been featured in numerous stories including articles appearing in Black Enterprise magazine, Contempora magazine, the Tennessee Tribune and the Urban Journal.

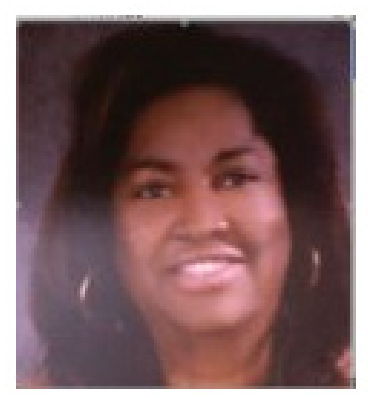

Dr. Retta Guy has an Ed.D. in Curriculum and Instruction with emphasis in Instructional Systems Design from the University of Kentucky. Currently, she is an Associate Professor in the Department of Business Information Systems at Tennessee State University in Nashville. Distance education, specifically online and mobile teaching and learning, serve as the basis for her current research for which she has presented at conferences and published nearly 25 articles and book chapters, collectively. Additionally, her second edited book on mobile learning is scheduled for release in July 2010. She has and continues to conduct workshops and training sessions on the use of Web-based course management tools as well as mobile learning technologies. 